\title{
Application of Frame Theory in Translation of Connotation in Chinese Ancient Poems
}

\author{
Mingjun Yao \\ Beijing Forestry University, Beijing, China \\ Email: yaomingjun1987@163.com
}

\begin{abstract}
Chinese ancient poems give prominence to the property of Chinese language that lay focus on the connotation beyond linguistic expressions. There has been long debate on which strategy should be chosen among literal or liberal translation and domestication or foreignization in translation community especially concerning cultural factors like translation of Chinese ancient poems. Frame theory provides a new perspective on the long debate of translation strategies, it illuminates on the translators that proper linguistic expressions should be found in target language to activate the identical or similar frames to those of in the source language.
\end{abstract}

Index Terms - frame, Chinese ancient poems, cultural frames, connotation, translation

\section{INTRODUCTION}

Translation studies have evolved greatly, increasingly taking on the interdisciplinary features. Anthropology, comparative linguistics, psycho-linguistics, socio-linguistics have been applied to illustrate translation studies by many scholars. The complication of translation process implies such a trend. Also the high frequency of intercultural communication has intensified this trend with the result that communicative perspective has become an important component in translation studies. The frame theory that would be applied in this paper on translation is compatible with the trend in translation studies. And it is also an effective communicative perspective in probing into translation, because translation is a cross-cultural activity essentially, and frame theory takes great consideration into cultural differences, which will be expounded on the following. According to Deng Jing (2010), the complicated translation process is not a simple activity of superficial linguistic decoding and encoding or rigid switches between languages. The author's intention, the target receiver's expectation and the translator's interpretation of the two sides should be taken due attachment. The new illumination on translation implies that studies on translation shouldn't be confined to superficial text or intra-linguistic aspect, and culture, society, politics as well as the translator's mental state should be components of translation studies.

Frame theory absorbed viewpoints from linguistics, psychology and artificial intelligence, comprehensively considering context, stereotype, perception and experience of agent. Therefore it can provide brand-new illumination on the complicated translation process and be high of value in studies on strategies of translation. However, the frame theory's application in translation studies is not as nourishing as expected (Deng, 2010). The review on the past literature on the application of frame in translation studies indicates that influential studies in such a perspective is rare and frame theory has not given a full play in translation studies. It is universally acknowledged that Chinese attaches great importance on expression of connotation or implicit meaning beyond superficial linguistic level, a semotactic language, which is opposite with English which has strict grammatical forms in expression, a morphotactic language. Chinese ancient poems, as the highly condensed Chinese, are laden with a sea of implicit meanings that should be fully grasped when translated into English. Successful convey of meaning of Chinese poems necessitates appropriate strategies or the target receiver would fail to feel the artistic conception disguised in the original poems.

The major task of translation of Chinese ancient poems is to perceive the implicit semantic relation and cultural information between lines. The paper will mainly explore strategies in translation of Chinese ancient poems by the application of frame theory.

\section{FRAME THEORY}

Frame theory was developed by Charles Fillmore with the purpose of showing a cognitive model for languages. Languages users interpret their surroundings, convey and comprehend messages and so on all according to their internalized frames. It gives prominence to the relationship between what a speaker says and the context in which he says it.

\section{A. Notion of Frame}

Fillmore's notion of frame originates from work conducted by Marvin Minsky, a computer expert in artificial intelligence in the 1970s. Concerning the notion of frame, Fillmore has given a series of definition of it. Initially, in 
1975, Fillmore first defined the notion of frame as any system of linguistic choices-the easiest cases being collections of words, but also including choices of grammatical rules of linguistic categories -that can get associated with prototypical instances of scenes (Ungerer\& Schimid, 2008). Such a definition means that a frame was regarded as any array of linguistic options which were connected with the "scenes", a notion similar to the term situation. The original notion of frames was indicative of a fact that frames has shifted towards cognitive interpretation. In 1985, Fillmore says that frames are specific unified frameworks of knowledge or coherent schematizations of experience. Still more recently he views frames as 'cognitive structures [...] knowledge of which is presupposed for the concepts encoded by the words'. The universally accepted notion of frame is that a frame is to be seen as a type of cognitive model which represents the knowledge and beliefs pertaining to specific and frequently recurring situation.

What this collection of definitions and explanations shows is that while frames were originally conceived as linguistic constructs, they have by now received a cognitive reinterpretation.

\section{B. Features of Frame}

From the analysis of our familiar commercial event frame [BUY] (because the [BUY] frame is so classic and familiar, here some details would be omitted), some features of frame can be derived(Wang, 2005).

Firstly, different cognitive perspectives within the same frame would result in different linguistic expressions. The verbs buy and pay describe the commercial event from the buyer's perspective, while sell and charge describe the situation from the seller's perspective. So the linguistic expressions would be different when different perspectives are adopted.

Secondly, components of a frame are basic and steady. In the classic commercial event frame, the basic and steady components are buyer, seller, goods and money, and accordingly in the [DANGER] frame, they are victim, tools and places.

Thirdly, all components which constitute the network of frames are closely connected. Once a component is mentioned, it will activate the whole cognitive frame. For instance, the word buy in commercial event frame would activate a whole bundle of other components which belong to the same frame. People grasp the meaning of the linguistic expressions largely depending on the activation of cognitive frames.

\section{Frame System and Sub-frames}

Any component of a frame can activate the whole frame which the component belongs to. In the [FLYING A PLANE] frame, the cognitive component plane would activate a whole bundle of other components which belong to the same [FLYING A PLANE] frame, such as pilot, flight attendant, life vest, safety belt, first class, economy class, safety instructions and so on. All these components and the specific relations that exist between them are part of the frame. But different components which activate the same frame would produce different perspectives. Such differences would lead to different frames in the same system. These different frames in the same system are regarded as frame system. Moreover, there are many so-called sub-frames which capture the knowledge of still more specific situations of a flight, such as [EATING], [WATCHING THE MOVIE] and [GOING TO THE TOILET]. Cognitive components play a major role within frames. Broadly speaking, components act as both anchors and triggers for frames, because it is in the format of components and their interrelations that frames are designed and it is by the same components that they are activated. A frame is composed of slots to which explicit or implicit information will be assigned when the frame is activated. As far as ancient Chinese poems concerned, more implicit information will be assigned. It indicates a further function of components is to provide so-called 'default assignments' (i.e. values for slots in the frame that apply under 'normal' conditions) by supplying context-dependent prototypes. For example, in the sub-frame of [EATING ON A PLANE] you will not expect to have your meal served on a huge dinner-table, set with expensive table-ware and a candle. As far as food and drinks concerned you will presumably not reckon with a gourmet meal accompanied by a vintage wine (unless you are used to flying first class). And it should be clear that the "default value" is also influenced by culture. Even the same frame will have different default value for cultural differences. For example, [CROW] in Chinese culture would be provided with default value-"hoodoo" or "bad luck", but in Japanese culture, [CROW] would be provided with default value-"auspiciousness". All these expectations that are based on our experience and stored in our long-term memory and influenced by specific cultural context are part of the frame-system and will influence our ability to produce and understand the related language.

Sub-frame and frame-system of [FLYING A PLANE] have no differences among all the languages, because the situation of flying a plane is almost the same all over the world. On the other hand, since people from different races, different regions or different languages have obviously different experiences, which have heavily influenced people's cognition, frame system and sub-frames. These different experiences would produce misunderstandings when communications take place between people from different races, places and language communities.

\section{Frame and Culture}

Frame is on the basis of conventional cultural knowledge, and more importantly, knowledge stored in a frame would be shared by a group of people in a language community. It proves that frame has innumerable links with culture. People living in the same culture share the same historic background and similar geographic condition. Their semblance of experience would produce the probability that they share the same frames to the same event. 
Moreover, there are many frames shared by the people all over the world, but in view of differences of experience, some frames are unique to specific cultural groups. Generally, on the basis of cultural differences, there are three situations concerning the different frames. Initially, there are frames shared by the largest number of people all over the world, such as [CINEMA] and [FLYING A PLANE]; The second are the frames that are unique to some specific cultures, for example, [KABUKI], it is unique to Japanese culture. The third are the frames that are shared by large numbers of people but differences can be perceived too, such as [FAMILY], in Chinese and English culture [FAMILY] all includes father and mother, but differently, in Chinese, it also comprises a child and grandparents, and in English culture it also includes children that has not been married and even their pet dogs, however, [FAMILY] in English culture doesn't include grandparent. Take an example of English-Chinese translation: Do you have a family? The sentence can’t be translated as “你有家庭吗 ${ }^{1}$ ?” or “你成家了吗?”. The correct translation is “你有孩子了吗 ${ }^{2}$ ?”. The incorrect translation results from not being clear about the differences lying in the shared frame.

\section{Frame Theory AND Chinese ANCIEnt Poems Translation}

It can be said that frame is a kind of implicit expression in a specific culture. In other words, frame can't be traced in linguistic expression structure, deeply ingrained in deep structure to organize knowledge so as to make linguistic expression sense in a specific cultural context. This point is conducive to the translation of Chinese ancient poems. True meaning of Chinese ancient poems is always obscured between lines; the translator should correctly grasp the knowledge of deep structure in the frame expressed in the poems and then seek the similar frames that can activate the artistic conception that is in line with the original poems to the target receiver in target language culture. According to the illustration of frame theory, the translator should initially have correct interpretation to the original poems depending on the stored or established frames in his mind and then find proper denotation of English language to reconstruct the poems so as to facilitate the target receivers' activation of the same or similar frame in their mind. The following sections are some translation examples on Chinese ancient poems by applying frame theory.

\section{A. Creation of Frames to Convey Connotation}

Chinese ancient poems are replete with specific cultural factors. Poets never thought that their poems would be disseminated into English culture. The shared knowledge between the poets and readers are left out in the poems. Chinese linguistic symbols activate the frames accordingly in the readers' mind. The default value filling the blanks in the poems enables the Chinese readers to understand the meaning in deep structure and appreciate the "beauty of artistic conception". The English readers are foreign to many Chinese cultural factors, the same frame may not activate the same frame in their mind, and so to attain the same effect on the English readers as on Chinese readers, the translator has to create new frames to convey the implicit meaning in Chinese ancient poems.

Sample1.

鹊桥仙-秦观

纤云弄巧,

飞星传恨,

银汉迢迢暗渡。

金风玉露一相逢,

便胜却人间无数。

Translation: Meeting across the Milky Way-Qin Guan(1049-1100, Song Dynasty of China), to the tune of Queqiaoxian

Through the varying shapes of the delicate clouds

The sad message of the shooting stars,

A silent journey across the Milky Way,

One meeting of the Cowherd and Weaver*

Amidst the golden autumn wind and jade-glistening dew,

Eclipses the countless meetings in the mundane world.

(Translated by Qiu Xiaolong)

According to a Chinese legend, two constellations the Cowherd and Weaver, separated by the Milky Way, are allowed to meet across a bridge formed by the magpies once a year on the seventh day of the seventh month in the Chinese lunar calendar.

In this Chinese ancient poem by Qin Guan, a poet in Song Dynasty, some specific cultural factors are involved. To Chinese readers, Cowherd and Weaver is a predestined match separated by the Milky Way. "Cowherd and Weaver" in the poem can activate [COWHERD AND WEAVER] with the default value "yearning", "separation", "bridge formed by magpies" and "the seventh day in the seventh month in Chinese lunar calendar". Chinese readers can understand the exuded emotion in the poems and perceive the enchanting of eternal love of the poet by the activated default values. The translator knows that English readers have not the same cultural frame and cannot fully understand the meaning

\footnotetext{
1 The literal meaning is 'Are you married?' in Chinese

2 It also can be understood as 'Do you have any children?'
} 
behind the conventional images-Cowherd and Weaver. Therefore, the translator provides extra cultural information in Chinese legend. It is through the creation a new frame in target receivers' mind that the translator successfully conveys the disguised meaning to the target readers.

\section{B. Modification on the Similar Frame}

Chinese readers can follow the poet by the natural assignment of default values activated by the related linguistic symbols or conventional images. But due to differences in experience from English readers, related linguistic symbols or images may activate frames that are partially different from those of Chinese readers in spite of similarities. That means that some default values activated by the same symbols are different in two cultures. To make the connotations sense in target readers' mind, some modification should be made.

Sample 2.

枫桥夜泊-张继

月落乌啼霜满天,

江枫渔火对愁眠。

姑苏城外寒山寺,

夜半钟声到客船。

Translation: Mooring near the maple bridge at midnight-Zhang Ji(712-715 to 779, Tang Dynasty of China)

The moon was setting, the crows were cawing, and the frost flurries in the sky.

The maples and fishing torches on the river kept me in my sad dream.

Our boat was moored near a monastery on the outskirts of Suzhou.

The midnight ringing of the temple bell seemed to announce our arrival.

(Translated by Qiu Xiaolong)

The classic poem was written after the failure in imperial examinations. The description on the landscape and images all mirrored the poet's gloomy mind and loneliness.

The setting moon, the cawing crow and fishing torches in the river all constitute a melancholy picture and depict the internal world of the poet. All these images can activate the frame [SADNESS] with the default value "bad luck", "setback" and "forlornness". It should be pointed out that the image "crow" in the first line thickens the sadness in poet mind and gives a hint of twisted destiny of the poet. So readers in Chinese culture can easily understand the feeling of the poet. However, the image "crow" in English culture is different from that of Chinese culture. In Chinese culture, the image of crow is inauspicious and can bring about bad luck, but in English culture, the default values of [CROW] is "vanity", "bragging" and "stupidity". To English readers, the image of crow may not be suitable with the atmosphere of the poem. So the translator made modification on the frame by giving some background knowledge to help the readers grasp the connotation of the poem.

\section{Addition of Default Value in the Poems}

As mentioned before, Chinese language pays more attention to connotations beyond linguistic expressions. The highly condensed linguistic expression of Chinese ancient poems gives high prominence to this characteristic of Chinese language. Poets were accustomed to employing the most succinct expression to present the heaps of feeling in their internal world. Therefore many components are deliberately omitted in Chinese ancient poems. These omitted components should be added when the poems are translated into English, because English language lays emphasis on the standard format expression.

Sample 3.-

春思-贾至

草色青青柳色黄,

桃花历乱李花香。

东风不为吹愁去,

春日偏能惹恨长

Translation: Spring feelings-Jia Zhi(718-772, Tang Dynasty of China)

The yellow willows wave above; green grass below;

Peach blooms run riot and plum blossom fragrant.

The vernal wind can never blow my grief away;

My woe increases with each lengthening spring day.

(Translated by Qiu Xiaolong)

In the original poem, the spatial position of willow and grass is not pointed out. Moreover, "whose-grief?" and "whose-woe?" are not told too in the Chinese version. But readers in Chinese culture can feel the description of landscape and the poet's grief and woe. The omission of the components can provide a touch of being personally on the scene. To Chinese reader, the characters in the poem can activate related frames naturally. Default values-above, below and $m y$ all can fill the blanks in the poem to perceive the poet's feelings. However, English language has strict format of linguistic expression, the omitted default values should be added or the translated version will not be coherent and eventually the connotation of the poem can't be interpreted by the target readers. 


\section{Addition of Default Value in the Poems}

The above strategies in previous sections can prevent the target readers from bewilderment from the clashes of frames in Chinese culture and English culture. However, such strategies may constitute obstacles in cultural communication, because translation also should play the role of disseminating Chinese culture to the target readers. Target readers must hope to read Chinese ancient poems with Chinese characteristics, so deliberate domestication is not proper.

Therefore, to let the target readers learn about the authentic Chinese culture, some frames that can lead to clashes of frames in two cultures can be made no alteration to just seek format equivalence.

Sample 4.

碧云天, 黄叶地, 西风紧, 北雁南飞, 晓来谁染霜林醉, 总是离人泪。- (关汉卿《西厢记》)

Translation: Grey are the clouds in the sky and faded are the leaves on the ground. Bitter is the west wind as the wild geese fly from the north to the south. How is that in the morning the white-frosted trees are dyed as red as a wine flushed face? It must have been caused by the tears of those who are about to depart (extracted from The Romance of the Western Chamber by Wang Shifu of Yuan Dynasty, translated by Xiong Shiyi ).

It is familiar to us that "west wind" in English culture is warm and moist. But in the translated version the frame was not alternated though it may cause conflicts of cultural frames. No alteration of frames in source language can further propel readers in English culture that are interested in Chinese culture to pursue the profundity of it.

\section{E. Illumination of Frame on Chinese Ancient Poems Translation}

It is a long tradition that translators all seek the equivalence between source language and target language in translation community. However, only equal face value was attained when translating but equivalence in deep level was neglected. It seems that disproportionate attention was paid to equivalence of format and cultural connotation deeply ingrained in culture was ignored with the result that literal translation was long preferred. Translation is based on the unit of culture, and its purpose is to meet the demand of exploring exotic culture of specific cultural groups. Chinese ancient poems are the crystallization of splendid Chinese culture, full of connotations that make sense only by depending on some frame systems that are different from other culture.

Professor Xu Yuanchong once proposed that "rhythmic beauty", "formal beauty" and "beauty of artistic conception" are three properties of Chinese ancient poems $(\mathrm{Xu}, 2004)$. To attain such beauties, poets always weighed word by word to voice their feeling with the most condensed language. Therefore, much shared knowledge between the poets and readers was omitted in poems. Poets deliberately left many blanks to the readers. The key to translate the Chinese ancient poems resides in maintaining "beauties" of original poems. The most important is to successfully convey the "beauty of artistic conception".

The poets and Chinese readers are immersed in the same cultural background, so the poet and the readers share almost the same frames, as enables the poets to write the poems with the most succinct language and shared knowledge was left out. Therefore connotations loaded between the lines need to be grasped by the activation of the familiar frames by the readers. Connotations in the poems are activated in the form of "default values" that fill the "blanks" left by the poets. So the exuded emotion or feelings and artistic conception can be understood by the readers.

Shared frames are the built bridges to connect the readers and the poets, facilitating the understanding to the poems. However, the English readers who live in a different culture are lack of the required cultural frames or different components to activate the same frames as the Chinese readers. It is not easy for them to fully understand Chinese ancient poems.

From the analysis of above sections, it can be concluded that frame theory can provide a new chink to cast light on the translation of Chinese ancient poems regardless of long debate on the choices of literal or liberal translation and domestication or foreignization and so on. It gives illumination on the translator that the priority in translation of Chinese ancient poems is to seek the most appropriate linguistic symbols to activate the similar or the same frames among the target receivers with the purpose of revealing the implicit meanings in the original poems.

\section{CONCLUSION}

The frame theory defines a cognitive frame in terms of a long established framework to be adapted to the reality, or of a network with components in the frame working harmoniously together. People all over the world are different in races, locations and languages, and these differences can lead to different experiences which largely influenced people's cognition, frame systems and sub-frames. There are polarities in frame systems, sub-frames and cultural frames between languages in the world. It is these polarities that produce some implicit information during the translation process, as is more apparent when Chinese ancient poems are translated into English.

As we know, linguistic expression functions both as triggers to activate and as anchors to stabilize the cognitive frames on which meaning depends. Beauty of artistic conception is the most important property of Chinese ancient poems. Artistic conception is disguised between the lines, and successful translation should also "translate" the artistic conception of the poems. The essence of translation is hence to seek in the in the target language the linguistic expressions to activate the cognitive frames identical or similar to those in source language. The harmony expressed in Chinese ancient poems should be reestablished by striving to avoid conflicts of frames when translate the Chinese 
ancient poems.

\section{REFERENCES}

[1] Deng, J. (2010). Translation studies from frame semantics. Foreign Language Teaching and Research, 1, 66-70.

[2] Hsiung, S. I. (1935). The Romance of the Western Chamber. London: Methune \& Co. Ltd.

[3] Qiu, X. L. (2003). Classic Chinese Love Poems. Shanghai: Shanghai Academy of Social Science Press.

[4] Ungerer, F. \& H. J. Schmid. (2008). An Introduction to Cognitive Linguistics. London: Longman.

[5] Wang, Z. Y. (2005). On translation from frame theory. Chinese Translators, 3, 27-32.

[6] Xu, Y. C. \& Tang, Z. D. (2004). 100 Tang and Song Quatrain Masterpieces by Great Poets. Jilin: Jilin Literature and History Press.

Mingjun Yao was born in Changde, Hunan Province of China on the $26^{\text {th }}$ of October, 1987, who has earned his bachelor degree of English language and literature at Humanities and Development College of China Agricultural University in 2010. And now he is a postgraduate student of foreign language and applied linguistics in Beijing Forestry University.

His current researches are mainly dedicated translation theory and practice. 